\title{
Influence of Aspergillus flavus Strains on Aflatoxin and Bright Greenish Yellow Fluorescence of Corn Kernels
}

\author{
Donald T. Wicklow, Bioactive Agents Research Unit, National Center for Agricultural Utilization Research, \\ USDA-Agricultural Research Service, Peoria, IL 61604
}

\begin{abstract}
Wicklow, D. T. 1999. Influence of Aspergillus flavus strains on aflatoxin and bright greenish yellow fluorescence of corn kernels. Plant Dis. 83:1146-1148.

The objective of this study was to relate the diversity of a naturally occurring population of Aspergillus flavus to their ability to contaminate grain with aflatoxin and produce bright greenish yellow fluorescent (BGYF) kernels. A total of 19 strains of A. flavus isolated from a corn field near Kilbourne, Illinois were used as inoculum, including 16 genotypes (DNA fingerprinting), and representing both aflatoxin producers and non-producers. A commercial corn hybrid (Pioneer 3394) was grown in this field in 1996 and 1998. A total of 20 ears in the late-milk to early-dough stage of maturity were inoculated with each A. flavus strain using a toothpickwound procedure. At harvest, 20 to 24 of the kernels nearest to each wounded site were separated into three categories: wound-inoculated kernels, intact BGYF kernels, and all other intact kernels. Sample weights of intact BGYF kernels in 1996 and 1998 grain samples averaged 5.0 and $9.5 \%$ of the total sample weight, respectively. Aflatoxin-producing strains were associated with a higher frequency $(P<0.05)$ of BGYF kernels for grain samples harvested in 1998. Removal of the individual wound-inoculated kernels and the intact BGYF kernels from corn ears inoculated with 13 aflatoxin-producing strains of A. flavus lowered mean aflatoxin values from $115 \mathrm{ng} / \mathrm{g}$ (range $=<1$ to $387 \mathrm{ng} / \mathrm{g}$ ) to $2 \mathrm{ng} / \mathrm{g}$ for 1996 grain samples and from $744 \mathrm{ng} / \mathrm{g}$ (range = 20 to $1,416 \mathrm{ng} / \mathrm{g}$ ) to $33 \mathrm{ng} / \mathrm{g}$ for 1998 grain samples. Results indicated substantial variation among A. flavus genotypes in their ability to produce aflatoxin in the germ and endosperm of infected BGYF kernels. The naturally occurring A. flavus population may include a majority of strains that produce no aflatoxin but exhibit BGYF and are thus aflatoxin "false positives" when corn grain is examined with an ultraviolet light at $365 \mathrm{~nm}$. Intraspecific competition between aflatoxin-producing and non-producing strains would be expected to naturally suppress the severity of aflatoxin outbreaks within the Midwestern corn belt.
\end{abstract}

Additional keywords: kojic acid, maize, mycotoxin, resistance, seed coat, temperature

The corn industry's first level of assessment for aflatoxin is the black-light test for kernels exhibiting bright greenish yellow fluorescence (BGYF; 14). The fluorescence is produced by the oxidative action of heat-labile enzymes (peroxidases) in living plant tissue on kojic acid, which is formed with aflatoxin by Aspergillus flavus Link:Fr. (10). The detection of BGYF in

Corresponding author: D. T. Wicklow

E-mail: wicklodt@mail.ncaur.usda.gov

Names are necessary to report factually on available data; however, the United States Department of Agriculture neither guarantees nor warrants the standard of the product, and the use of the name by the USDA implies no approval of the product to the exclusion of others that may also be suitable. All programs and services of the USDA are offered on a nondiscriminatory basis without regard to race, color, national origin, religion, sex, age, marital status, or handicap.

Accepted for publication 4 September 1999.

Publication no. D-1999-1015-01R

This article is in the public domain and not copyrightable. It may be freely reprinted with customary crediting of the source. The American Phytopathological Society, 1999. undamaged kernels is evidence that $A$. flavus has infected the germ or endosperm.

However, predicting aflatoxin levels is difficult based on the proportion of BGYF kernels or kernel fragments in grain samples $(3,8)$. One reason for this is that kernels infected with $A$. flavus strains that produce kojic acid but do not produce aflatoxin exhibit BGYF and thus are aflatoxin "false positives" when corn grain is examined with a black light. Quantities of aflatoxins are greater when $A$. flavus grows saprotrophically in damaged kernel tissues than when the germ and endosperm of intact kernels are infected $(12,19)$. Aflatoxin concentrations in wound-inoculated corn kernels grown in the University of Wisconsin Biotron ranged from 13,200 to $82,000 \mathrm{ng} / \mathrm{g}$ (mean, 36,700 $\mathrm{ng} / \mathrm{g}$ ), while the sample means for intact kernels surrounding each wound site did not exceed 2,100 $\mathrm{ng} / \mathrm{g} \quad(=2,100 \mathrm{ppb})$ and concentration ranged from 154 to $6,290 \mathrm{ng} / \mathrm{g}$ (18). Unfortunately, no attempt was made to separate BGYF kernels or to record aflatoxin concentration in these kernels.

Naturally occurring populations of $A$. flavus may vary in their pathogenicity or virulence (2) and their ability to produce aflatoxin (1). A. flavus isolates from corn harvested at the University of Illinois River Valley Sand Field (IRVSF, Kilbourne, IL) were characterized recently using DNA fingerprinting and the ability to produce aflatoxin in laboratory culture (20). The objective of this study was to determine whether the naturally occurring diversity in this collection of A. flavus isolates from Illinois corn is related to their ability to produce BGYF kernels and aflatoxin following wound inoculation.

\section{MATERIALS AND METHODS}

Fungal inoculum and culture conditions. All A. flavus strains examined in this study were isolated from corn sampled at harvest from an experimental planting ( $<1.5$ ha) under continuous (1988 to 1991) corn cultivation at IRVSF (20). The ability of 121 A. flavus strains from IRVSF to form sclerotia and to produce aflatoxin in laboratory culture was described previously. The genotype of each strain was characterized based on DNA fingerprinting (20). On the bases of these data (20), a total of 19 strains were selected to represent strains that produce or do not produce aflatoxin in our current study (Table 1). Conidia from each strain were harvested from 14-day-old Czapek agar slants incubated at $25^{\circ} \mathrm{C}$, after adding $5 \mathrm{ml}$ of $0.01 \%$ Triton X-100 to each slant. Cultures then were agitated, and the spore suspensions transferred to sterile screw-capped culture tubes and adjusted to $1 \times 10^{-6}$ spores $/ \mathrm{ml}$ with sterile distilled water. The spore suspensions were stored at $4^{\circ} \mathrm{C}$ for 3 days prior to corn inoculations.

Commercial hybrid and field location. In 1996 and 1998, a commercial corn hybrid (Pioneer 3394) was grown to maturity in a 16-ha field at IRVSF, Kilbourne, Illinois. An area within the center-pivot-irrigated portion of this field was selected for A. flavus inoculations. The plot (30 by 40 m) consisted of 10 rows of corn, each $40 \mathrm{~m}$ in length. Eight border rows separated the plot from the nearest access road. A total of 20 ears on plants within a single 7-m length of row were inoculated with one of the A. flavus strains. Each of the inoculated 7-m row lengths were separated by four noninoculated plants.

Inoculation procedure. Corn ears in the late-milk to early-dough stage of kernel maturity (about 21 days after mid-silk; 7 August 1996 and 24 July 1998) were wound inoculated with a conidial suspen- 
sion of A. flavus. Ears were inoculated at three points separated by $4 \mathrm{~cm}$ in a vertical row. A sterile wooden toothpick was inserted through the husk to wound an underlying kernel. A second toothpick, contaminated with A. flavus spore suspension, was then inserted into each wound site and left until ears at $15.5 \%$ moisture content were hand harvested on 2 October 1996 and 19 October 1998.

The 20 kernels nearest to each wound site (18) were separated into three categories: wound-damaged kernels, intact BGYF kernels as determined with an ultraviolet light at $365 \mathrm{~nm}$, and the remaining kernels. All A. flavus strains sporulated on woundinoculated kernels, evidence of successful fungal establishment at the site of wounding. Kernels were not sampled from portions of ears with visible insect damage. Kernels molded by fungi other than $A$. flavus also were excluded. Each category of kernels was pooled within each A. flavus strain, weighed (Table 1), and stored in plastic bags at $-7^{\circ} \mathrm{C}$ prior to aflatoxin analyses.

Aflatoxin analyses. All of the grain sampled from ears inoculated with each $A$. flavus strain and separated according to BGYF kernels versus non-BGYF kernels was first ground using a Stein Mill (Steinlite Inc., Atchison, KS). All samples were analyzed for aflatoxins by the Aflatest (Vicam Inc. Watertown, MA) procedure according to the manufacturer's instructions. A total of $5 \mathrm{~g}$ of $\mathrm{NaCl}$ was added to $50 \mathrm{~g}$ of ground corn sample (approximately 150 kernels), which was then blended for 1 min with $100 \mathrm{ml}$ of $80 \% \mathrm{MeOH}$ in water (vol/vol) and filtered through Whatman $2 \mathrm{~V}$ filter paper (filtrate no. $1=0.5 \mathrm{~g}$ equiva- lent $/ \mathrm{ml}$ ). Next, $10 \mathrm{ml}$ of filtrate no. 1 was diluted with $40 \mathrm{ml}$ of distilled water $(=5 \mathrm{~g}$ equivalent $/ 50 \mathrm{ml}$ ) and filtered through a microfiber filter, after which $10 \mathrm{ml}$ of filtrate no. 2 (= $1 \mathrm{~g}$ equivalent $/ 10 \mathrm{ml})$ was passed through an Aflatest affinity column. The column was washed twice with distilled water and the aflatoxin concentrated in $1 \mathrm{ml}$ of $100 \% \mathrm{MeOH}$. Following the addition of $1 \mathrm{ml}$ of bromine developer, aflatoxin concentration was determined with a Vicam Series-4 fluorometer calibrated with Vicam test solutions. For samples of intact BGYF kernels weighing 3.7 to $22.2 \mathrm{~g}$ (10 to 60 kernels), the method was adjusted to scale for quantity of sample. $\mathrm{NaCl}(0.1 \mathrm{~g})$ and $2 \mathrm{ml}$ of $80 \% \mathrm{MeOH}$ were added to each $1 \mathrm{~g}$ of sample in a stoppered 125-ml Erlenmeyer flask. Flasks were shaken vigorously on a wrist-action shaker for $5 \mathrm{~min}$, and the contents filtered through Whatman $2 \mathrm{~V}$ filter paper. Filtrate no. 1 was diluted $(1: 4 \mathrm{vol} / \mathrm{vol})$ with distilled water and filtered through a microfiber filter, then a measured volume of filtrate no. 2 was passed through an affinity column. Samples of wound-inoculated kernels, appearing damaged and shriveled and weighing 0.5 to $3.0 \mathrm{~g}$ (20 to $40 \mathrm{ker}-$ nels), were repeatedly steeped in $10 \mathrm{ml}$ of chloroform on 3 successive days, and 30 $\mathrm{ml}$ of total extract was combined in a silated vial stored at $-21 \mathrm{C}$. Following drydown of chloroform under air, several grains of $\mathrm{NaCl}$ and appropriate volumes (1.0 to $6.0 \mathrm{ml}$ ) of $80 \% \mathrm{MeOH}$ were added to individual sample vials and vortexed for 5 min. Non-filtered $\mathrm{MeOH}$ extract $(0.5$ to $3.0 \mathrm{ml})$ was diluted $(1: 4 \mathrm{vol} / \mathrm{vol})$ with distilled water ( 2 to $12 \mathrm{ml}$ ), passed through a $0.4-\mu \mathrm{m}$ pore syringe filter, passed through an affinity column, concentrated in $1 \mathrm{ml}$ of $100 \% \mathrm{MeOH}$, developed, and read in the fluorometer. Total sample aflatoxin levels for each inoculation treatment were calculated using the formula: [wounded kernels $(\mathrm{g}) \times$ aflatoxin $(\mathrm{ng} / \mathrm{g})+$ intact BGYF kernels $(\mathrm{g}) \times$ aflatoxin $(\mathrm{ng} / \mathrm{g})+$ all other kernels $(\mathrm{g}) \times$ aflatoxin $(\mathrm{ng} / \mathrm{g})] /$ total sample weight $(\mathrm{g})$.

A Student's $t$ test was applied at a 5 or $1 \%$ level of probability to compare the following sample means: percent weight of BGYF kernels for A. flavus strains that produce aflatoxin $(n=13)$ and those that do not $(n=6)$; aflatoxin (ng/g) content of grain samples for A. flavus strains that produce aflatoxin harvested in $1996(n=$ $13)$ and $1998(n=13)$; and aflatoxin ( $\mathrm{ng} / \mathrm{g})$ content of grain samples $(n=13)$ before and after the removal of the wounded kernels and the intact BGYF kernels.

\section{RESULTS AND DISCUSSION}

In 1996, kernels that were wound inoculated with 1 of 19 A. flavus strains and intact BGYF kernels comprised 0.4 to $1.0 \%$ (mean, $0.6 \%$ ) and 1.5 to $11.5 \%$ (mean, 5.0\%) of the total sample based on weight, respectively (Table 1). In 1998, wound-inoculated and intact BGYF kernels comprised 0.1 to $0.4 \%$ (mean, $0.3 \%$ ) and 2.6 to $14.8 \%$ (mean, $9.5 \%$ ) of the total sample, respectively, based on weight. The ability of $A$. flavus strains to produce aflatoxin was associated with a significantly greater frequency of BGYF kernels (as determined by sample weight) for grain samples harvested in 1998, but not for grain samples harvested in 1996. The number of intact BGYF kernels may be associated with frequency of seed coat

Table 1. Aflatoxin contamination of corn kernels (hybrid Pioneer 3394) wound-inoculated with 19 strains of Aspergillus flavus isolated from corn

\begin{tabular}{|c|c|c|c|c|c|c|c|c|c|c|c|c|}
\hline \multirow[b]{3}{*}{ Strains $^{\mathrm{a}}$} & \multicolumn{6}{|c|}{ Grain at harvest, 1996} & \multicolumn{6}{|c|}{ Grain at harvest, 1998} \\
\hline & \multicolumn{2}{|c|}{ Sample weight $(\%)$} & \multicolumn{3}{|c|}{ Aflatoxin (ng/g) } & \multirow[b]{2}{*}{ Total $^{\mathbf{d}}$} & \multicolumn{2}{|c|}{ Sample weight (\%) } & \multicolumn{3}{|c|}{ Aflatoxin (ng/g) } & \multirow[b]{2}{*}{ Total $^{\mathrm{d}}$} \\
\hline & Wounded & BGYF $^{\mathbf{b}}$ & Wounded & BGYF & Other $^{c}$ & & Wounded & BGYF $^{\mathbf{b}}$ & Wounded & BGYF & Other $^{\mathrm{c}}$ & \\
\hline A-27837 & 0.8 & 2.8 & 13,600 & 3,800 & 3 & 215 & 0.3 & 11.0 & 2,200 & 6,400 & 43 & 747 \\
\hline 26474 & 0.9 & 7.8 & 16,600 & 2,900 & 14 & 387 & 0.4 & 10.8 & 1,800 & 8,700 & 19 & 965 \\
\hline 26473 & 0.5 & 6.6 & 12,200 & 1,500 & $<1$ & 164 & 0.2 & 14.8 & 2,000 & 9,200 & 7 & 1370 \\
\hline $26491^{x}$ & 0.5 & 3.0 & 10,800 & 1,200 & 4 & 93 & 0.3 & 12.0 & 2,100 & 5,200 & 5 & 634 \\
\hline 26482 & 0.4 & 4.9 & 14,800 & 1,100 & 3 & 113 & 0.3 & 13.5 & 3,300 & 9,200 & 190 & 1416 \\
\hline 26468 & 0.9 & 8.0 & 13,000 & 900 & 1 & 191 & 0.4 & 13.7 & 1,400 & 9,200 & 12 & 1,283 \\
\hline 26480 & 0.6 & 2.9 & 17,200 & 200 & $<1$ & 108 & 0.2 & 13.3 & 1,700 & 7,200 & 36 & 990 \\
\hline $26485^{x}$ & 0.4 & 3.1 & 6,000 & 300 & $<1$ & 40 & 0.3 & 9.6 & 4,200 & 8,900 & 42 & 904 \\
\hline A-27676 & 0.5 & 3.9 & 8,800 & 52 & $<1$ & 45 & 0.1 & 4.8 & 1,100 & 150 & 12 & 20 \\
\hline 26477 & 1.0 & 1.5 & 2,000 & 71 & 0 & 21 & 0.2 & 10.2 & 160 & 610 & 1 & 64 \\
\hline $26476^{y}$ & 0.4 & 4.4 & 1,060 & 67 & 0 & 7 & 0.3 & 10.8 & 620 & 1,840 & 14 & 212 \\
\hline $26479^{y}$ & 0.5 & 4.5 & 2 & 0 & 0 & $<1$ & 0.1 & 6.5 & 0 & 990 & 2 & 66 \\
\hline 26472 & 0.6 & 4.4 & 280 & 0 & 0 & 2 & 0.4 & 5.6 & 4,400 & 4,200 & 9.4 & 262 \\
\hline $26641 *$ & 0.6 & 7.4 & 102 & 1 & 0 & $<1$ & 0.2 & 9.0 & 0 & $<1$ & 1.7 & 2 \\
\hline $26639 *$ & 0.6 & 6.2 & 240 & 4 & 0 & 2 & 0.3 & 7.9 & $<1$ & 90 & 5.5 & 12 \\
\hline A-27675* & 1.0 & 11.5 & 0 & 0 & 0 & 0 & 0.4 & 9.5 & 0 & 0 & 0 & 0 \\
\hline $26640 *$ & 1.0 & 5.3 & 3 & 0 & 0 & $<1$ & 0.2 & 8.8 & 0 & 0 & 4.2 & 4 \\
\hline A-27667*z & 0.4 & 2.6 & 4 & 3 & 3 & $<1$ & 0.3 & 2.6 & 310 & 86 & 0.1 & 3 \\
\hline $\mathrm{A}-27668^{* \mathrm{z}}$ & 0.4 & 4.3 & 6 & 0 & $<1$ & $<1$ & 0.2 & 6.4 & 0 & 42 & 0 & 3 \\
\hline
\end{tabular}

a NRRL strain numbers; ${ }^{*}=$ aflatoxin negative $(-)$ on glucose yeast extract soytone (GYES) medium (20) as determined by thin-layer chromatography; ${ }^{\mathrm{x}, \mathrm{y}}$ and ${ }^{\mathrm{z}}$ indicate NRRL strains sharing a common genotype.

b BGYF = intact, bright greenish-yellow fluorescent kernels.

c Other intact kernels.

d Total sample. 
tearing. A. flavus colonizes the woundinoculated kernels and uses them as a food base from which to spread and infect the surrounding intact kernels $(6,15,18,19,22)$. Zuber (21) and others have observed that A. flavus is a weak pathogen of maize and that infection of the grain usually requires a break in the pericarp $(4,7)$. However, the fungus can easily enter the air spaces of the pericarp but cannot infect the germ or endosperm unless a break occurs in the internal seed coat or testa (16). Smart et al. (16) showed that $A$. flavus gains entry to the germ through random microscopic breaks in the testa when the surrounding pericarp was intact. Aflatoxin is produced after the fungus invades the embryo or endosperm. The scattered distribution of undamaged BGYF kernels removed from the same ear $(5,9,15)$ may simply mirror the distribution of kernels having torn seed coats (16).

Aflatoxin levels for wound-damaged kernels inoculated with 1 of the 13 aflatoxin-producing $A$. flavus strains exceeded $1,000 \mathrm{ng} / \mathrm{g}$ for 11 samples in 1996 and 10 samples in 1998 (Table 1). These lightweight, wound-damaged, and shriveled kernels did not exceed $1 \%$ of the total sample weight for grain harvested from any inoculation treatment or year. Aflatoxin levels for samples of intact BGYF kernels infected with 1 of the 13 aflatoxin positive strains varied from 0 to $3,800 \mathrm{ng} / \mathrm{g}$ in 1996 and from 150 to $9,200 \mathrm{ng} / \mathrm{g}$ in 1998. The 1998 values proved to be significantly higher $(P<0.01)$. When the aflatoxin content of each fraction was combined as the weighted mean for each of the treatments inoculated with 1 of the 13 aflatoxin positive strains, 10 grain samples harvested in 1996 and 13 grain samples harvested in 1998 had unacceptable aflatoxin concentrations $(>20 \mathrm{ng} / \mathrm{g}$ ). The removal of individual wound-inoculated kernels and intact BGYF kernels from grain samples harvested in 1996 and 1998 resulted in a significant $(P<0.01)$ reduction of the mean aflatoxin values from 115 to $2 \mathrm{ng} / \mathrm{g}$ and from 744 to $33 \mathrm{ng} / \mathrm{g}$, respectively.

Differences in aflatoxin levels and the frequency of BGYF kernels between years may be explained by differences in the average daily temperatures recorded at Illinois Climate Network, Champaign, IL (IRVSF) for September $1996\left(16.6^{\circ} \mathrm{C}\right)$ and September $1998\left(20.6^{\circ} \mathrm{C}\right)$, with the warmer temperatures favoring $A$. flavus parasitic ability and aflatoxin production $(5,17)$. The extent to which a corn hybrid develops symptoms of $A$. flavus kernel rot and the accumulation or aflatoxin within individual, infected kernels is positively related to temperature during the period of grain filling and maturation (17) and drought stress (11). The present results show that BGYF kernels become contaminated with different amounts of aflatoxin because $A$. flavus strains differ in their basic ability to produce aflatoxins. Both aflatoxin-positive and aflatoxin-negative strains produced BGYF kernels. The naturally occurring $A$. flavus population may include a majority of strains that produce no aflatoxin $(13,20)$ but exhibit BGYF and are thus aflatoxin "false positives" when corn grain is examined with an ultraviolet light at $365 \mathrm{~nm}$. Interpretations of the association between weight of BGYF kernels and aflatoxin levels in grain samples (3) should recognize the aflatoxin-producing potential of the A. flavus population in regions where corn is grown. Intraspecific competition between aflatoxin-producing and non-producing strains would be expected to naturally suppress the severity of aflatoxin outbreaks within the Midwestern corn belt.

\section{ACKNOWLEDGMENTS}

I thank C. E. Platis and R. Cristobal for technical assistance; and an anonymous reviewer for valuable suggestions for improving an earlier draft of the manuscript.

\section{LITERATURE CITED}

1. Bayman, P., and Cotty, P. J. 1993. Genetic diversity in Aspergillus flavus: association with aflatoxin production and morphology. Can. J. Bot. 71:23-31.

2. Cotty, P. J. 1989. Virulence and cultural characteristics of two Aspergillus flavus strains pathogenic on cotton. Phytopathology 79:808814.

3. Dickens, J. W., and Whitaker, T. B. 1981. Bright greenish-yellow fluorescence and aflatoxin in recently harvested yellow corn marketed in North Carolina. J. Am. Oil Chem. Soc. 58:973A-975A.

4. Guo, B. Z., Russin, J. S., Cleveland, T. E., Brown, R. L., and Widstrom, N. W. 1993. The role of the pericarp of corn kernels to reduce infection and aflatoxin production by Aspergillus flavus. Phytopathology 83:14171418.

5. Jones, R. K., Duncan, H. E., Payne, G. A., and Leonard, K. J. 1980. Factors influencing infection by Aspergillus flavus in silk-inoculated corn. Plant Dis. 64:859-863.

6. King. D. B., and Scott, G. E. 1982. Field inoculation techniques to evaluate maize for reaction to kernel infection by Aspergillus flavus. Phytopathology 72:782-785.

7. Koehler, B. 1957. Pericarp injuries in seed corn. Prevalence in dent corn and relation to seedling blights. Univ. Ill. Agric. Exp. Stn. Bull. 617, Urbana.

8. Kwolek, W. F., and Shotwell, O. L. 1979. Aflatoxin in white corn under loan. V. Aflatoxin prediction from weight percent of bright greenish-yellow particles. Cereal Chem. 56:342-345.

9. Lee, L. S., Lillehoj, E. B., and Kwolek, W. F. 1980. Aflatoxin distribution in individual corn kernels from intact ears. Cereal Chem. 57:340-343.

10. Marsh, P. B. Simpson, M. E., Ferretti, R. J., Merola, G. V., Donoso, J., Craig, G. O., Trucksess, M. W., and Work, P. S. 1969. Mechanism of formation of a fluorescence in cotton fiber associated with aflatoxin in the seeds at harvest. J. Agric. Food Chem. 17:468-472.

11. Payne, G. A., Cassel, D. K., and Adkins, C. R. 1986. Reduction in aflatoxin contamination incorn due to irrigation and tillage. Phytopathology 76:679-684.

12. Scott, G. E, Zummo, N., Lillejoj, E. B., Widstrom, N. W., Kang, M. S., West, D. R., Payne, G. A., Cleveland, T. E., Calvert, O. H., and Fortnum, B. A. 1991. Aflatoxin in corn hybrids field inoculated with Aspergillus flavus. J. Agron. 83:595-598.

13. Shearer, J. F., Sweets, L. E., Baker, N. K., and Tiffany, L. H. 1992. A study of Aspergillu flavus/parasiticus in Iowa crop fields: 19881990. Plant Dis. 76:19-22.

14. Shotwell, O. L., and Hesseltine, C. W. 1981. Use of bright greenish-yellow fluorescence as a presumptive test for aflatoxin in corn. Cereal Chem. 58:124-127.

15. Smart, M. L., Shotwell, O. L., and Caldwell, R. W. 1990. Pathogenesis in Aspergillus ear rot of maize: Aflatoxin B1 levels in grains around wound-inoculation sites. Phytopathology 80:1283-1286.

16. Smart, M. J., Wicklow, D. T., and Caldwell, R. W. 1990. Pathogenesis in Aspergillus ear rot of maize: light microscopy of fungal spread from wounds. Phytopathology 80:1287-1294.

17. Wicklow, D. T. 1994. Preharvest origins of toxigenic fungi in stored grain. Pages 10751081 in: Stored Product Protection. E Highley, E. J. Wright, H. J. Banks, and B. R. Champ, eds. CAB International, Wallingford, England.

18. Wicklow, D. T., Horn, B. W., and Shotwell, O. L. 1987. Aflatoxin formation in preharvest maize ears co-inoculated with Aspergillus flavus and Aspergillus niger. Mycologia 79:679682.

19. Wicklow, D. T. , Horn, B. W., Shotwell, O. L., Hesseltine, C. W., and Caldwell, R. W. 1988. Fungal interference with Aspergillus flavus infection and aflatoxin contamination of maize grown in a controlled environment. Phytopathology 78:68-74.

20. Wicklow, D. T., McAlpin, C. E., and Platis, C. E. 1998. Characterization of the Aspergillus flavus population within an Illinois corn field. Mycol. Res. 102:263-268.

21. Zuber, M. S. 1977. Influence of plant genetics on toxin production in corn. Pages 173-179 in: Mycotoxins in Human and Animal Health. J. V. Rodricks, C. W. Hesseltine, and M. A. Mehlman, eds. Pathotox Publishers, Park Forest South, IL

22. Zummo, N., and Scott, G. E. 1989. Evaluation of field inoculation techniques for screening maize genotypes against kernel infection by Aspergillus flavus in Mississippi. Plant Dis. 73:313-316. 